\title{
São Leopoldo pelo olhar dos viajantes: 1834-1906
}

\author{
São Leopoldo look for travellers: \\ 1834-1906
}

Eloisa Helena Capovilla da Luz Ramos*

Resumo: O trabalho pretende ver a cidade de São Leopoldo no Sul do Brasil, através do relato de viajantes europeus e latino-americanos que a percorreram entre os anos de 1834 e 1906. Na perspectiva do "olhar estrangeiro", alguns marcadores podem ser destacados da vila e depois cidade de São Leopoldo entre os quais o que a distinguia como uma "cidade alemã". Contribuiu para a construção desta visão entre outros aspectos, o uso da língua alemã (dialetos) e a forma como os imigrantes organizavam e usavam a cidade e seu entorno, quer para o trabalho, quer para o lazer e a sociabilidade.

Palavras-chave: São Leopoldo. Viajantes. Olhar estrangeiro. Cidade alemã.

Abstract: This paper aim to view the city of São Leopoldo in the South of Brazil, through the report of Europeans travellers and Latin-Americans who wandered in this place between the years of 1834 and 1906. In the prespective of the "Foreign Eyes ", a marker of that can be seen in some features of the village and later from the city of São Leopoldo among those is what distinguished it as a "German City". Contruibuted to this vision amongst other things the use of the German language (dialects) and the manner how the immigrants organized and lived in the city around them, either for work, for leisure or sociability.

Keywords: São Leopoldo. Travellers. Foreign eyes. German city.

* Doutora em História pela Universidade Federal do Rio Grande do Sul (2000). É professora da Graduação e do Programa de Pós-Graduação em História da Universidade do Vale do Rio dos Sinos - UNISINOS. 


\section{Introdução}

Este texto tem como escopo analisar o espaço da vila e depois cidade de São Leopoldo a partir de relatos de alguns viajantes estrangeiros que visitaram a localidade ao longo do século XIX e início do XX. Consideramos nessa análise que a localidade, uma antiga fazenda real, a Real Feitoria do Linho Cânhamo, transformara-se de acordo com Portaria do Governo Imperial (Piccolo: 1974, p. 10-11), em área própria para receber imigrantes alemães, em julho de 1824. Ao longo do século a "Colônia Alemã de São Leopoldo" (Piccolo: 1974, p. 11) transformouse em local importante no contexto da colonização do Rio Grande do Sul como espaço ocupado por imigrantes alemães e por luso-brasileiros. É nessa condição que foi visitada por um significativo número de viajantes de diferentes países europeus e latino-americanos entre os quais citamos Arsène Isabelle, Nicolau Dreys, Juan Maria Gutierrez, Alexandre Baguet, Michael Mulhall, Hans Hofmann e Vittorio Buccelli.

$\mathrm{Na}$ leitura mais atenta dos escritos de viajantes estrangeiros ao Rio Grande do Sul ou ao Brasil percebemos baseadas em alguns estudiosos (Freixa: 1993; Pratt: 1999; Burke: 2000), que tais escritos eram, muitas vezes, receitas dadas em livros sobre a arte de viajar [...] ou mesmo, afirmações feitas em livros, por viajantes anteriores (Burke: 2000, p. 140-141). O mesmo autor aponta ainda que

Algumas dessas descrições são [...] escritas com a publicação em mente, e tudo segue em consideração a certas convenções literárias. Outras, apenas refletem preconceitos no sentido literal de opiniões formadas antes que os viajantes deixassem seu próprio país, sejam essas opiniões resultado de conversas ou leituras (Burke: 2000, p. 139).

Em tais compêndios, cartas ou diários outros autores como Freixa (2000) alertavam que para ser um bom viajante nessa época era necessário uma preparação prévia que incluía entre outros aspectos ter dinheiro, conhecer as leis do seu país, conhecer entre outras ciências história natural, mineralogia e química. Deveria também o viajante conhecer geografia, agricultura e línguas, assim como saber desenhar [...] e, ainda, para ter melhores resultados deveria ter conhecimentos de medicina e música, porque isto lhe ajudaria a introducirse en las sociedades cultivadas y procurarle valiosas amistades (1993, p. 48). A estas necessidades era ainda imprescindível, segundo o mesmo autor, ter bom estado físico, escolher um bom criado e trazer algumas cartas 
de recomendação para apresentá-las às autoridades que representassem o seu próprio país no sítio visitado, como embaixadores, cônsules ou outros. Peter Burke (2000: 142) constata que de qualquer modo, o ingresso em uma cultura estranha ou semiestranha transforma o viajante em espectador, observador, se não em voyeur [...].

A compreensão do 'outro' foi, assim, mediada pelo seu (des) conhecimento aliado à sua bagagem cultural, por um lado. Por outro, consideramos que o valor destas visões sempre pode ser apreendido pelo pesquisador para o conhecimento do passado de vilas, cidades e de outros espaços, assim como de suas gentes desde que tomadas como fontes e tendo o cuidado de não perder de vista os pontos destacados por estes informantes.

Mary Louise Pratt (1999), outra estudiosa do tema aponta uma série de aspectos que devem ser considerados quando se analisam textos de viajantes europeus dos séculos XVIII e XIX, pois estes se apresentavam geralmente eivados de conceitos e preconceitos oriundos de suas observações e da superioridade que julgavam ter sobre os outros povos.

Tomando em consideração o espaço construído por imigrantes alemães e teuto-brasileiros em São Leopoldo a partir da observação, descrição e, muitas vezes, desenhos e fotografias fornecidos pela escrita desses viajantes, queremos dar a ver o município e a cidade que os outros viram, ou seja, queremos destacar elementos que informem a respeito da história da cidade e seu entorno, retirados desses textos. Para alcançar nosso objetivo, organizamos os escritos numa perspectiva cronológica e os analisamos considerando três pontos básicos: (1) a viagem (Porto Alegre-São Leopoldo); (2) a vila/cidade (urbanização, comércio, indústria); (3) a população (alemães e brasileiros).

\section{A viagem}

A imigração alemã para São Leopoldo a partir de 1824 trouxe para este lado do Atlântico uma população cuja bagagem cultural era diferenciada da que aqui se encontrava quer pelo idioma, quer pela religião reformada ou a forma de trabalhar a terra, entre outros aspectos. Tinham esses imigrantes, consequentemente, uma outra visão de mundo. Assim, passadas as dificuldades iniciais de adaptação ao novo lugar, imprimiram o ritmo de vida da colônia que, nesse período, tinha o Rio dos Sinos como sua principal artéria de ligação com a capital da Província. Isto chamou a atenção dos viajantes estrangeiros que chegaram a São Leopoldo. Entre os primeiros que ali estiveram 
destacamos Arsène Isabelle, viajante francês que visitou o Rio Grande do Sul em 1833/1834. Depois de uma viagem bastante longa por um rio que considerou sinuoso, o visitante avistou a vila por entre árvores e uma mata verde "luxuriante". Ao avistá-la pensou estar na Alemanha, tais as características europeias que viu na vila. Interessado na natureza anotou que encontrara nos arredores de São Leopoldo (Barreto: 1973, p. 790) "18 espécies de madeiras úteis; 17 espécies de fungos e duas novas espécies de lepidópteros, oriundas de São Leopoldo".

No ano de 1845, Juan Maria Gutierrez (1946), viajante argentino e comerciante, relata sua viagem a S. Leopoldo descrevendo-a assim:

Para ir desde Puerto Alegre á la Colonia de San Leopoldo, pueden tomar-se dos caminos: por tierra e por el Rio dos Sinos. En el primer caso se andan ocho léguas atravesando el Rio Gravatahy: en el segundo se navegan quince, á causa de las muchas vueltas ó tortuosidades del rio (p. 103).

Minucioso, o viajante continua relatando a viagem:

Yo sali para la Colonia em la tarde del 12 de Setiembre y llegué á ella á las nueve de la noche del 14, embarcado en uno de los venticuatros lanchones que trafican entre la Capital y San Leopoldo [...]. los hay capaces de cargar trecientos sacos de maiz [...]. Los pasageros se acomodan muy mal sobre las desigualdades de la carga $[\ldots]$ (p. 103).

O Rio dos Sinos, segundo Gutierrez é um rio de muitas curvas, mas suas margens estão

plantadas por la natureza de arboles, no corpulentos, pero ricos de verdur y em vejetacion parasita. El água escorrentosa y de buen sabor aunque amarillea á causa del lecho de arena y tierra fangosa sobre que corre [...]. Em el curso de la navegacion hasta $\mathrm{S}$. Leopoldo, se hacen frecuentes paradas para dar descanso á los remadores $[\ldots](105)$.

Juan Maria Gutierrez aponta, por fim, que a localização da vila ficava na margem esquerda do Rio dos Sinos a $29^{\circ} 45$ de latitude Sul e $7^{\circ} 55$ a Oeste do Meridiano do Rio de Janeiro. No intuito de reforçar o que descrevia o viajante também usou o recurso do desenho para destacar o tipo de embarcação usado no Rio dos Sinos e também o que enxergava da vila desde o rio, na altura do "passo". Este recurso, 
apontado por Freixa (2000) como importante para ser um viajante, fazia parte da bagagem cultural de Juan Maria Gutierrez.

A viagem a São Leopoldo na perspectiva de A. Baguet (1997), viajante belga que se dirigia ao Paraguai, neste mesmo ano de 1845 não priorizou a paisagem ou mesmo alguma característica especial. Sem estender-se numa descrição pormenorizada ele diz que a colônia alemã de São Leopoldo "foi fundada às margens do rio dos Sinos, numa vasta planície rodeada de montes e florestas, a uma distância de cerca de sete léguas, por terra, de Porto Alegre" (1997, p. 35).

Robert Avé-Lallemant (1980), médico alemão, era, como os homens do seu tempo, dotado de espírito irrequieto e aventureiro o que o levou a fazer longas viagens e a morar por muitos anos no Rio de Janeiro. No ano de 1858 fez uma viagem ao Sul do Brasil onde visitou diversas localidades, dando especial destaque àquelas habitadas por patrícios alemães. Na sua viagem entre Porto Alegre e São Leopoldo num vaporzinho dirigido com "agradável pachorra alemã" observou que o Rio dos Sinos era "um rio deliciosamente calmo", com águas verdes e com uma exuberância de árvores, flores e folhas ao longo do caminho. Das moitas, diz o viajante, quando o barco passava, levantava "uma multidão de coloridas borboletas [...]. Assim viajamos cerca de sete horas" (p. 114-116). São Leopoldo apontou o autor, começava na margem do Rio dos Sinos.

Em livro de autor desconhecido (1988), publicado na Alemanha em 1869, o autor, que seria um alemão retornado, vai dizer, sucintamente, que fez a viagem entre Porto Alegre e São Leopoldo de vapor e que

depois de termos deixado o lago, pelo norte, entramos no Rio dos Sinos junto ao qual fica São Leopoldo e depois de 6 horas de viagem lá chegamos. São Leopoldo é o nome do lugar onde o rio oferece um 'passo', isto é, onde se pode atravessá-lo. Aqui o rio é largo mas raso tanto que pode-se atravessá-lo a cavalo (apud Müller, 1988, p. 89).

Num outro momento da vida da cidade de São Leopoldo, Vittorio Buccelli (1906), um viajante italiano a visitou, em viagem por várias cidades do Rio Grande do Sul. O trabalho, encomendado pelo Estado para propaganda do Rio Grande do Sul na Exposição de Milão, em 1906 (conforme Barreto, 1973, p. 214), resultou em interessantes informações sobre os lugares visitados. É o caso de São Leopoldo. A viagem entre Porto Alegre e esta cidade feita de trem, permitiu que o viajante pudesse observar a paisagem pelo caminho. Assim, na primeira parada do trem, em Canoas, a observação foi que se tratava de "um ponto delicioso de 
veraneio (p. 305)" muito frequentado e com casas elegantes. A outra estação era a de Sapucaia, onde avistou figueiras centenárias assim como plantações de mandioca. Depois de uma hora de viagem chegou à estação de São Leopoldo. O caminho não foi só descrito, foi também ilustrado com duas fotografias.

Atualizava-se a viagem com o trem e a máquina fotográfica no início do séc. XX, mas o olhar do viajante ainda era o olhar do outro, do europeu sobre nós. A continuação dos relatos confirma o que dizemos.

\section{A vila/cidade}

Um visitante, quando chega a um lugar é, acima de tudo um observador e ao exercer esta atividade, o faz usando sua bagagem cultural, sua compreensão de mundo. Ou, como aponta Pratt (1999), com os "olhos do Império" se for um europeu. É o que acontece com Isabelle quando chega a São Leopoldo: fui surpreendido pelo contraste que ofereciam esses lugares cultivados com cuidado [...] estas pequenas propriedades, esta atividade de agricultores e artesãos [do lado alemão] [...] com o abandono absoluto em que os brasileiros deixam suas terras (sic).

Olhando a vila, as casas e as atividades econômicas que se desenvolviam em São Leopoldo Arsène Isabelle (1983) notará que:

Havia então [...] perto de 150 casas de madeira e tijolo, contendo uma população de 1.000 almas [...] é habitada principalmente por artesãos alemães tais como marceneiros, ferreiros, fabricantes de carroças, sapateiros, alfaiates, seleiros, funileiros e por negociantes que são taberneiros, marceneiros, alborcadores, tanto alemães como de outros países [...]. Outros alemães, possuindo algum capital, formam estabelecimentos mais ou menos importantes, tais como curtumes, distilarias, serrarias, fábricas de fósforos, olarias e engenhos de farinha de mandioca e açúcar (1983, p. 73-74).

Isabelle anota ainda que as autoridades da colônia são brasileiras, compondo-se de um juiz de paz e de um comandante militar. $\mathrm{Na}$ descrição de Isabelle fica patente o olhar comparativo com a "Alemanha conhecida". A pequena localidade habitada por um número significativo de imigrantes alemães só poderia se parecer com a cidade europeia, segundo o viajante!

No final desta mesma década, outro viajante francês, Nicolau Dreys, comerciante durante muitos anos na capital da Província, Porto 
Alegre, e conhecedor da Colônia de São Leopoldo, descreveu-a como uma área de colonização recente, que produzia víveres para alimentar os mercados da Capital desorganizado ao tempo da Revolução Farroupilha. São Leopoldo destacava-se segundo este viajante, também pelos "bons ares" que recuperavam a saúde de muitos rio-grandenses, o que lhe dava certa notoriedade!

Juan Maria Gutierrez (1946) de quem já falamos anteriormente nos informa sobre a vila dizendo que os edificios públicos se reduzem a duas Igrejas uma católica e outra luterana, ambas de material e uma sala de baile, limpa e espaçosa. Quase todas as casas são oficinas e armazéns (1983, p. 104). No interior da colônia, diz Gutierrez, há tendas, pulperias, salas de baile e capelas para culto. $\mathrm{O}$ relato deste observador/viajante é ilustrado pelo desenho da Igreja e da casa ao seu lado. A barca em que viajou e o morro de Sapucaia também mereceram registro assim como o Rio dos Sinos em frente à colônia e onde se destacam a Rua do Passo e a praça.

Alexandre Baguet, que vivia como um autêntico flanêur (1997, p. 8), descreveu o centro de São Leopoldo dizendo que havia ali "olarias, curtumes, distilarias e serrarias" (1997, p. 35). É, diz ele, uma destas raras colônias do Brasil que, organizando-se por si mesmas, alcançam um alto nível de prosperidade, que só tem aumentado (1997, p. 35).

Müller (1988, p. 90) ao trazer à cena o relato de um autor desconhecido, sobre a colônia de São Leopoldo, descreveu a vila assim:

na margem do rio está o lugarejo São Leopoldo, um núcleo 'totalmente germânico', embora construído segundo orientação brasileira. Somente no extremo sul da vila moram algumas famílias brasileiras. No lugarejo só se ouve o dialeto renano, misturado com palavras portuguesas, embora a maioria fale o prtuguês. [...] Devem ser, ao todo 200 casas. Em cada casa há uma taberna, negócio ou oficina (apud Müller: 1988, p. 90).

O mesmo autor destacou, em seu texto, que esta vila possuía "moendas de cana, alambiques, fábricas de chapéus, cervejarias, fábricas de cola, pequenas indústrias de variada ordem, tanto que um enviado prussiano que visitou São Leopoldo disse em alta voz: 'eu pensei estar numa vila de colono, mas achei uma cidade de fábricas!” (Müller, 1988, p. 90).

Robert Avé Lallemant (1980) outro viajante alemão que ficou bastante entusiasmado com os seus patrícios do Sul do Brasil viu São Leopoldo como uma pequena Alemanha. Fez um longo relato sobre a 
presença alemã na Vila (criada como vila em 1846) e em seus costumes. Destacamos deste relato a fala sobre o centro da vila e da rua principal:

as casas se enfileiram ininterruptamente, muitas delas assombradas e com até seis janelas de largura, mas em sua maioria térreas, de construção maciça, cobertas de telha, com aparência de lugar abastado ou mesmo rico. Todavia, a longa rua, apesar das calçadas ao longo das casas, não tem calçamento, é mais funda no meio e um tanto arenosa, conservando, assim, seu aspecto aldeão. Em algumas casas tocava-se piano [...]. Depois acendeu-se a luz e via-se gente de todos os ofícios, sapateiros, alfaiates, carpinteiros, etc. trabalhando mais um pouco para terminarem a semana (1980, p. 116-117).

Internamente a vila de São Leopoldo destacava em Relatório de 1854, de seu vereador presidente João Daniel Hillebrand, a necessidade do Código de Posturas ser direcionado para atender aos interesses econômicos que nela se desenvolviam. A vila de São Leopoldo é uma vila inteiramente industrial. [...], portanto tudo quando forem posturas tendentes a agastar o lugar [...] é [uma forma de] promover a sua ruína e obstruir o seu desenvolvimento ${ }^{1}$.

Analisando estas falas percebemos que o desenho que esses viajantes fizeram de São Leopoldo em seus primeiros 60 anos é de duas ordens: a primeira mostra o centro urbano em crescimento com um grande número de artesãos e um comércio em crescimento. O resultado da afirmação pode ser visto, também, nas casas que são descritas como bastante sólidas, algumas, grandes e, em cujo interior aparecia algum luxo, como o piano ou os espelhos e a máquina de costura, que também eram sinais de distinção destacados por Lallemant. A segunda, percebida nas franjas desta mesma leitura, mostra São Leopoldo até o final dos anos 1870 como uma cidade onde a infra-estrutura ainda era precária. Assim, embora progressista e movimentada, o seu planejamento urbano apresentava-se incipiente. Havia um traçado regular das ruas, havia praças, havia preocupações explicitadas no Código de Posturas com relação a muitos aspectos da vila. Entretanto, algumas obras importantes ainda não haviam sido concretizadas. Neste sentido, constatamos, por exemplo, a falta de calçamento nas ruas principais assim com a falta da

A crítica de Hillebrand era exatamente aos cuidados que o Código de Posturas da Vila apresentava para a existência de determinados tipos de indústria (art. 19) na área urbana, pois estas, caso não fossem permitidas, poderiam prejudicar o desenvolvimento e o conceito de progresso aí embutido. 
ponte sobre o Rio dos Sinos, fator importante para ligar os dois lados da vila, assim como ligar a vila com a colônia em seu lado norte.

Os viajantes que estiveram em São Leopoldo da década de 1870 em diante viram uma outra cidade (elevada a cidade no ano de 1864). Nessa época as ligações da cidade com as colônias e com a Capital da Província já estavam concluídas. A partir de então São Leopoldo viverá outro momento, sobretudo do ponto de vista econômico. Uma amostragem deste crescimento apareceu na presença de produtos de São Leopoldo nas exposições industriais realizadas pelo Governo Provincial ou Estadual em 1866, 1875, 1881 e 1901.

No início do século XX, Vittorio Buccelli destacava em São Leopoldo uma série de estabelecimentos industriais muito prósperos e cita, entre outros estabelecimentos, a fábrica de chapéus de G. Eggers, a fábrica de sabão do Sr. L. Hoffmann, as fábricas de bebidas e licores de Bier, Wolffenbüttel, Weinmann, Dihel e a serraria do Sr. Feldmann. Chama nossa atenção, outra vez, as fotografias que ilustram a obra de Buccelli, porque nos dão a dimensão da época e destacam o que mais chamava a atenção do viajante, ou melhor o que mais lhe interessava, visto ser um europeu cujo olhar para a localidade era mediado pela sua bagagem cultural e por seus interessas na região.

Os viajantes, assim como os historiadores, os memorialistas, os cronistas e porque não, os políticos, entre outros, olharam, leram e descreveram o traçado urbano de São Leopoldo, tanto no passado como ainda hoje. Espaços polissêmicos, vilas e cidades podem ser descritas e lidas de muitas maneiras, mas sabemos também que quem as descreve traz de antemão um modelo, uma cidade idealizada [a sua Veneza, como diria Marco Polo ao Grande Kan] e que na medida em que vê e descreve a outra cidade, o descritor/leitor a compara com aquela que tem em mente.

\section{A população}

Em se tratando da população de São Leopoldo no período estudado, os viajantes serão, de certo modo, testemunhas. Juan Maria Gutierrez (1946) dirá que "os colonos se sentem bem no país, e não têm antipatia nem pela língua nem pelos costumes brasileiros: é muito comum ouvi-los falar o português (p. 105). Comentará que os imigrantes vivem bem, tendo comida boa e em abundância e também os móveis necessários para a vida. As mulheres lavram a terra com seus pais ou maridos assim como governam um lanchão ou montam a cavalo. Em São Leopoldo, 
quase todos os domingos se juntam a bailar desde que começa a tarde até depois da meia noite. Dança-se com muito respeito (Gutierrez, 1946, p. 109-110).

Amado (1978) e Roche (1969), entre outros autores que escreveram sobre a Colônia Alemã de São Leopoldo destacam que foi a partir de 1845, com o término da Revolução Farroupilha que São Leopoldo deu o grande salto para o desenvolvimento econômico (1978, p. 66). Nesse processo foram os comerciantes os que se mostraram como os mais preparados, diz Janaína Amado.

Lallemant sublinhará, que é "completamente aldeão o aspecto de sua gente" (1980, p. 117) quando falar da população da vila de São Leopoldo, no final dos anos 1850. Naquele momento, a sua população (a vila e os arrabaldes) [era] de 1.068 habitantes, composta, na maior parte, de mecânicos, obreiros e artífces, dizia em Relatório o presidente da Câmara Municipal João Daniel Hillebrand.

Michael Mulhall ${ }^{2}$ visitou a cidade em 1871, quando da inauguração da estrada de ferro entre Porto Alegre e S.Leopoldo. Sua narrativa destacava, na ocasião, os festejos realizados na igreja [que, dizia] está ornamentada com bom gosto [...] [e] os habitantes da vila estão todos com roupas domingueiras [...], todas as fábricas e serrarias estão silenciosas, como acontece no domingo de manhã [...]. O cenário festivo do dia é a estação provisória (1974, p. 95). "Um pavilhão fronteiriço" continuou o autor, "coberto com telhado contra o sol tropical, foi reservado para as damas, que vão embelezar a ocasião [...]. Fora do recinto acha-se uma ramada [...] sob a qual vai assar-se a carne bovina [...] para a multidão" (1974, p. 95-96).

No final desta mesma década, Hans Hofmann, (1878), vai dizer sobre São Leopoldo "nossa permanência na querida e germânica São Leopoldo vai chegando ao fim e é hora de voltar o olhar para a colonia alemã [...]" (p. 230). Dirá também este viajante que

nós já tínhamos notado que os colonos conservavam sua língua materna na terra estranha e que muitas vezes a gente tem a impressão de estar na Alemanha. Este fato é tão marcante que os próprios filhos dos colonos aqui nascidos, em geral não falam português (1878, p. 230).

\footnotetext{
Jornalista inglês que veio a São Leopoldo cobrir a inauguração da Estrada de ferro Porto Alegre-São Leopoldo e que publicou em Londres, no ano de 1873, o livro Rio Grande do Sul and Its German Colonies, cujo capítulo 10 se referia a São Leopoldo. Tradução de Telmo Lauro Müller: 1974.
} 
Escrevendo sobre a cidade e sua população dirá que a cidade é industrializada e própria para o comércio. Sua população consiste, diz ele, em uma maioria oriunda do Palatinado e da região do Reno, além dos nascidos na Prússia. Os imigrantes são em parte católicos e em parte evangélicos. Depois, diz,

Em muito, como já disse, a vida em São Leopoldo pode igualar-se a uma cidadezinha alemã. A vida social concentra-se principalmente em algumas sociedades, das quais já citei o 'Orpheu'. Também existe uma sociedade de tiro, que de tempos em tempos promove um campeonato. Nós assistimos durante a nossa estadia a um baile dessa sociedade (Hofmann, apud Müller, 1974, p. 236-7).

Falar da população de São Leopoldo, de seus hábitos e costumes, de sua religiosidade ou de seu idioma a partir dos relatos de viajantes que a visitaram é sublinhar a germanidade do grupo imigrante, destacada por quase todos. A permanência da língua alemã como traço cultural permitiu ao viajante pensar que estava na 'pequena Alemanha' ou 'numa cidade alemã' num período em que esta sequer existia. Isto é muito significativo porque sublinha a comunidade imaginada tanto pelos imigrantes quanto pelos viajantes. E, se ao mesmo tempo se destacava a melhoria das condições econômicas do grupo e o caráter industrial e industrioso de seu povo é também dizer da sua competência por ser alemão (o que fazem alguns viajantes mais explicitamente). Quanto à rusticidade desses homens e mulheres nos primeiros tempos da imigração, apontado por alguns viajantes, pode ser lido como uma qualidade do ser alemão, isto é, ser trabalhador. Assim, o deslocamento para uma área pouco ou nada civilizada [no caso, o Brasil] vai contribuir para o desenvolvimento do processo civilizatório em moldes europeus.

Tomando em conta o crescimento da cidade verificamos que os viajantes perceberam, também, o refinamento dos costumes dos imigrantes alemães de São Leopoldo na segunda metade do séc. XIX, ao destacar sua vida social em sociedades recreativas oriundas das tradições alemãs como a Sociedade Orpheu e a Sociedade de Tiro. A par desta melhor condição de vida ficava o progresso com a chegada do trem e ampliavam-se as possibilidades econômicas dos diversos setores comerciais e industriais da cidade.

\section{A guisa de conclusão}

No período enfocado por este texto, os imigrantes, como portadores de uma cultura própria eram os outros em São Leopoldo e o seu espaço 
de representação era, por isso mesmo, mais restrito. Assim, construíam na vila/cidade espaços que eram não só frutos do desenvolvimento econômico que imprimiram ao lugar, mas representações de sua cultura e, ao mesmo tempo, espaços capazes de dizer, simbolicamente, de sua competência. Isto é ressaltado nas visitas e relatos que inúmeros viajantes fazem a São Leopoldo ao longo dos seus primeiros 70 anos de vida com olhares distintos e cor interesses diferenciados, mas sublinhando sempre a partir do conhecimento da sua origem, a germanidade do mesmo na época estudada.

Sabemos, também, a partir dos estudos sobre a imigração, que $a$ 'transição' quebra, de uma forma muito inclusiva e sem discriminação, as tradições, identidades e formas de vida (Monteiro, 1993, p. 323). Entretanto, de alguma forma há na bagagem de quem emigra muito do que viveu em sua terra natal. Os emigrantes procuram encontrar e construir redes de sociabilidade nos países onde se instalam, e uns constroem-na de uma forma, outros de outra. (Monteiro, 1993, p. 325). É preciso tentar compreender, portanto, o processo pelo qual certas pessoas emigraram e foram, ao longo do tempo, organizando as suas vidas noutros lugares (Monteiro, 1993, p. 323).

\section{Referências}

AMADO, Janaína. Conflito Social no Brasil: a revolta dos "mucker". Rio Grande do Sul 1868-1898. São Paulo: Símbolo, 1978. (Coleção ensaio e memória, 5).

AVÉ-LALLEMANT, Robert. Viagem pela Província do Rio Grande do Sul (1858). Belo Horizonte: Ed. Itatiaia; São Paulo: Ed. da Universidade de São Paulo, 1980.

BAGUET, Alexandre. Viagem ao Rio Grande do Sul. Santa Cruz do Sul: EDUNISC; Florianópolis: PARAULA, 1977.

BARRETO. Abeillard. Bibliografia Sul-Riograndense. Rio de Janeiro: Conselho Federal de Cultura, 1973. v. 1 e 2.

BUCCELLI, Vittorio. Um viaggio a Rio grande del Sud. Milano: L.F. Pallestrini, 1906.

BURKE, Peter. Variedades da história cultural. Rio de Janeiro: Civilização Brasileira, 2000 .

DREYS, Nicolau. Notícia descritiva da Província de S. Pedro do Sul. 4. ed. Porto Alegre: Nova Dimensão/EDIPUCRS, 1990.

FREIXA, Consol. Los ingleses y el arte de viajar. Barcelona: Ediciones del Serbal, 1993.

GUTIERREZ, Juan Maria. ‘Apuntes sobre la colônia alemana de San Leopoldo’ en la Provincia del Rio Grande del Sur en el Brasil (Recojidos sobre los mismos lugares, en el mes de setiembre de 1845). In: Boletim Municipal do Município de São Leopoldo, São Leopoldo: PMSL, ano 1, v. 1, n. 1, p. 101-118, 1946. 
HILLEBRAND, João Daniel. Relatório do Diretor da Colônia de São Leopoldo Dr. João Daniel Hillebrand apresentado ao Presidente da Província, Angelo Muniz da Silva Ferraz. Revista do Arquivo Público, Porto Alegre, n. 15 e 16, 1924.

HOFMANN, Hans. Nach Brasilien und Zurück in die Heimat. Cap. 10. Tradução de Telmo Lauro Müller. In: Anais do Primeiro Simpósio da Imigração e Colonização Alemã no Rio Grande do Sul. São Leopoldo: Rotermund, 1974.

ISABELLE, Arsène. Viagem ao Rio Grande do Sul (1833-1834). 2. ed. Porto Alegre: Martins Livreiro, 1983.

MONTEIRO, Miguel. Migrantes e emigrantes de Fafe (1834-1926): territórios, estrutura social e itinerários. In: JORNADAS DE HISTÓRIA LOCAL, 1 ${ }^{\text {ss }}$, Fafe, Câmara Municipal de Fafe, 1996.

MULHALL, Michael G. Inauguração da Estrada de Ferro de São Leopoldo. Tradução de Arthur Rabuske. In: Estudos Leopoldenses, São Leopoldo: UNISINOS, n. 28, p. 94-100, 1974.

MÜLLER, Telmo Lauro. Herança de geração em geração. São Leopoldo: Rotermund, 1988.

PICCOLO, Helga Iracema Landgraf (Coord). Levantamento e apreciação de problemática de São Leopoldo no período de 1824-1889'. In: Estudos Leopoldenses, São Leopoldo: UNISINOS, n. 28, p. 5-59, 1974.

PRATT, Mary Louise. Os olhos do Império. Relatos de viagem e transculturação. Bauru, SP: EDUSC, 1999.

ROCHE, Jean. A colonização alemã e o Rio Grande do Sul. Porto Alegre: Globo, 1969. v. I e II. (Coleção Província). 